\title{
SISTEM PELAPORAN JUMLAH PENDUDUK DESA KEMBANGSERI KECAMATAN BERMANI ILIR KABUPATEN KEPAHIANG PROVINSI BENGKULU
}

\author{
Sapri, Hermawansa \\ Program Studi Sistem Informasi Fakultas Ilmu Komputer Universitas Dehasen Bengkulu \\ J1, Meranti Raya No. 32 Kota Bengkulu 38228 Telpon (0736) 22027,26975 Fax. (0736) 341139 \\ e-mail :sapriukubaru@yahoo.co.id, hermawansalyahoo.co.id
}

\begin{abstract}
Villagers are groups of relatively small areas within an area that are bound by applicable regulations and interact with each other continuously or continuously. Population development will be influenced by the number of babies born, the number of deaths, out-migration (moving) and in-migration (incomers). The problem in this study is how the Population, Death, Birth, and Outgoing Migration (migrants) Reporting System uses a programming language. The benefits of research are to facilitate the population reporting system, make it easier for village officials to record population numbers, births, deaths, in-migration, and out-migration quickly and effectively, make it easier for people to get information on population numbers, births, deaths, out-migration, and in-migration (comer). The purpose of this research is to create new technology in the world of the village government with a special programming language (Visual Basic.Net). in the village government of Kembang Seri, Bermani Ilir District, Kepahiang Regency, Bengkulu Province. Literature research methods and primary and secondary data collection methods in providing public services to the community require a system that can help local governments, especially in Kembangseri Village, Bermani Ilir District, Kepahiang Regency, Bengkulu Province in terms of a Reporting system for population, births, and deaths, out-migration (moving) and in-migration (newcomers) using a special programming language (Visual Basic.Net).
\end{abstract}

Keywords: Birth, Death, Outgoing Migration, and Inward Migration.

\begin{abstract}
Abstrak - Penduduk Desa adalah kelompok wilayah yang relatif kecil di dalam suatu wilayah yang terikat oleh aturan-aturan yang berlaku dan saling berinteraksi satu sama lain secara terus menerus atau kontinu. Perkembangan penduduk akan dipengaruhi oleh jumlah bayi yang lahir, jumlah kematian, migrasi keluar (pindah) dan migrasi masuk (pendatang). Adapun masalah dalam penelitian ini adalah bagaimana cara Sistem Pelaporan Jumlah Penduduk, Kematian, kelahiran, migrasi keluar (pindah) migrasi masuk (pendatang) dengan menggunakan bahasa pemrograman. Manfaat penelitian untuk memudahkan sistem pelaporan jumlah penduduk, Memudahkan Perangkat desa mendata jumlah Penduduk, kelahiran, kematian, migrasi masuk dan migrasi keluar dengan cepat dan efektif, Memudahkan masyarakat untuk mendapatkan Informasi jumlah penduduk, Kelahiran, kematian, migrasi keluar (pindah) dan migrasi masuk (pendatang). Tujuan penelitian ini untuk membuat teknologi baru dalam dunia pemerintahan desa dengan bahasa pemrograman khusus (Visual Basic.Net). pada pemerintahan desa Kembang Seri Kecamatan Bermani Ilir Kabupaten Kepahiang Provinsi Bengkulu.Metode penelitian Kepustakaan dan Metode Pengumpulan data Primer dan Sekunder dalam penyelenggaraan pelayanan publik kepada masyarakat membutuhkan Suatu sistem yang dapat membantu Pemerintah daerah khususnya di Desa Kembangseri Kecamatan Bermani Ilir Kabupaten Kepahiang Provinsi Bengkulu dalam hal Sistem Pelaporan jumlah penduduk, kelahiran dan kematian, migrasi keluar (pindah) dan migrasi masuk (pendatang) dengan menggunakan bahasa pemrograman khusus (Visual Basic.Net).
\end{abstract}

Kata Kunci: Kelahiran, Kematian, Migrasi Keluar dan Migrasi Masuk.

\section{I. $\quad$ PENDAHULUAN}

Pertumbuhan penduduk merupakan keseimbangan yang dinamis antara kekuatan- kekuatan yang menambah dan kekuatan yang mengurangi jumlah penduduk. Secara terus menerus penduduk akan dipengaruhi oleh jumlah bayi yang lahir tetapi secara bersamaan pula akan dikurangi oleh jumlah kematian yang terjadi pada semua golongan umur. Sementara itu emigran (keluar) dan migrasi (masuk) berperan akan menambah dan akan mengurangi jumlah penduduk.
Muncul permasalahan yang dialami didaerah/desa yang belum menggunakan sistem aplikasi/ pemrograman khusus. Terutama dalam mendata jumlah penduduk, kelahiran, kematian, Migrasi keluar dan migrasi masuk, pada desa tersebut. Biasanya daerah/desa yang belum menggunakan sistem aplikasi/pemrograman mengalami kesulitan ketidak cocokan data yang ada di kantor desa dengan fakta yang ada dilapangan.

Sesuai dengan pembahasan diatas, maka peneliti ingin mengetahui bagaimana sistem pelaporan jumlah penduduk, jumlah kelahiran dan 
kematian, migrasi keluar dan migrasi masuk Oleh karena itu peneliti melakukan penelitian yang mengangkat Studi kasus "SISTEM PELAPORAN JUMLAH PENDUDUK DESA KEMBANG SERI KECAMATAN BERMANI ILIR KABUPATEN KEPAHIANG PROVINSI BENGKULU.

\section{TINJAUAN PUSTAKA}

\section{A. Pengertian Sistem}

Sistem merupakan kumpulan elemen yang saling berkaitan yang bertanggung jawab memproses masukan (Input) sehingga menghasilkan keluaran (Output)[1].

Beberapa buku menjadi tinjauan pustaka yang digunakan untuk mewujudkan tulisan ini dan ada juga Beberapa buku pendukung teori adalah sebagai berikut: Lembaga Demografi Fakultas Ekonomi Universitas Indonesia "Dasar-Dasar Demografi“" [2] menerangkan pengetahuan tentang kependudukan adalah sangat penting untuk lembaga-lembaga swasta maupun pemerintah baik ditingkat nasional maupun daerah. Perencanaan - perencanaan yang berhubungan dengan pendidikan, kesejahteraan sosial, perumahan, dan perusahaan-perusahaan yang memproduksi barang dan jasa, jalan-jalan, rumah-rumah, dan pusat rekreasi akan menjadi lebih tepat apabila kesemuanya didasarkan pada data kependudukan. Maka hal yang dilihat adalah dari pertumbuhan lapangan pekerjaan dan persentase penduduk yang ada disektor pertanian.

Setelah Inggris meninggalkan Indonesia, Belanda meneruskan pelaksanaan registrasi tersebut namun hingga pertengahan Abad ke-19 perhatiannya justru hanya sedikit data registrasi yang diterbitkan.

Setelah tahun 1850 pemerintah penjajahan Jepang menghapus sistem registrasi dan di ganti sistem vital[3]. Sistem registrasi penduduk diteruskan lagi dikecamatan menyerahkan perubahan-perubahan penduduk yang ada selama seminggu didesanya[4].

\section{B. Komponen Sistem Informasi}

Sistem informasi merupakan Komponen yang saling berinteraksi satu dengan yang lain membentuk suatu kesatuan untuk mencapai sasaran.

1. Komponen input

2. Komponen model

3. Komponen output

4. Komponen teknologi

5. Komponen perangkat keras (hardware)

6. Komponen perangkat lunak (software)

7. Komponen basis data (database)

8. Komponen kontrol

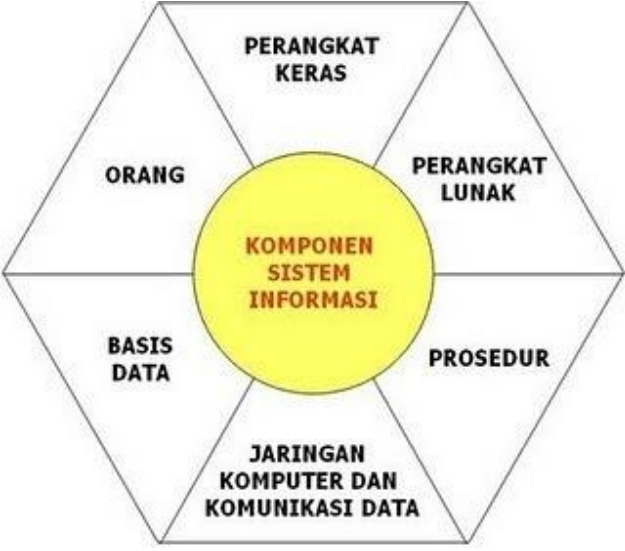

Gambar 1. Komponen Sistem Informasi

\section{Metode Waterfall Model}

Metode waterfall yaitu menggambarkan pendekatan yang sistematis dan juga berurutan pada pengembangan perangkat lunak, dimulai dengan spesifikasi kebutuhan pengguna lalu berlanjut melalui tahapan-tahapan perencanaan (planning), permodelan (modeling), konstruksi (construction)[5].

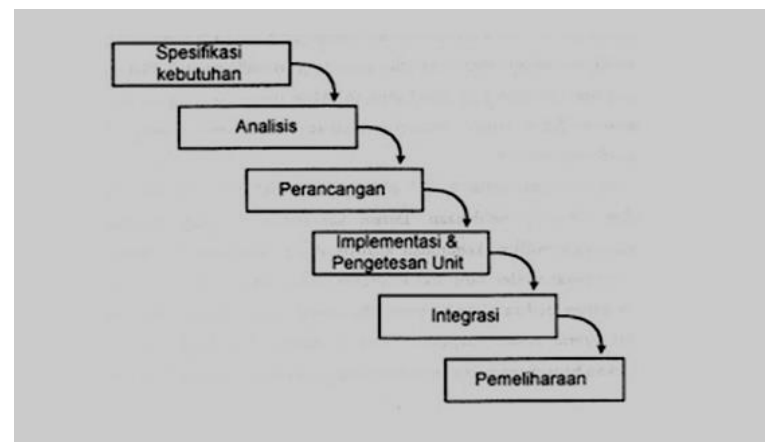

Gambar 2. Metode Waterfall

Sistem ditafsirkan sebagai kesatuan elemen memiliki keterkaitan. Beberapa elemen dapat menjadi suatu unit, kelompok atau komponen sistem dengan fungsi tertentu[6].

\section{Tinjauan Umum Perangkat Lunak VB .Net}

Visual Basic .Net adalah generasi selanjutnya dari Visual Basic. Visual Basic .Net memungkinkan untuk membangun aplikasi databaseclient atau server performa tinggi dan sangat cocok didampingkan dengan perangkat lunak $S Q L$ Server. .NET Framework merupakan model platform yang memudahkan dalam membangun lingkungan aplikasi yang terdistribusi di Internet. Platform .Net Framework terdiri dari dua bagian utama [7].

Adapun Menu yang terdapat pada Visual Basic.Net, seperti terlihat pada gambar di bawah ini: 


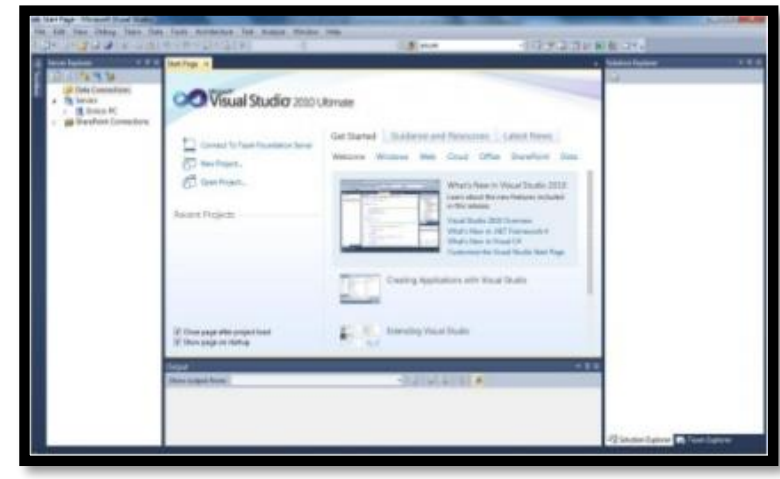

Gambar 3. Visual Basic .Net

\section{E. SQL Server $2008 r 2$}

SQL Server merupakan suatu Relational Database Management Sistems (RDBMS) yang digunakan untuk menyimpan data. Data yang disimpan pada database bisa dalam skala kecil maupun besar. Selain itu, penyajiannya merupakan penyajian pada level fisik karena kita akan menyimpan langsung data pada database dengan kondisi yang sebenarnya, yaitu disimpan pada tabel apa, kolom mana, dan menggunakan tipe data saat [8].

Operasi yang biasanya dilakukan database berhubungan erat dengan pengaksesan tabel atau query [9].

\section{a. Date Data Type \\ b. Data Compression \\ c. Sparse Column \\ d. Row Constructor}

\section{III.. METODE PENELITIAN}

\section{A. Waktu dan Tempat Penelitian}

Dilaksana pada bulan maret 2020 - Desember 2020, tempat penelitian dilaksanakan di Kantor Desa Kembang Seri dengan studi kasus "Sistem Pelaporan Jumlah Penduduk Desa Kembang Seri Kecamatan Bermani Ilir Kabupaten Kepahiang Provinsi Bengkulu.

\section{B. Metode penelitian Penelitian Kepustakaan (Library Research)}

Informasi yang dibutuhkan melalui membaca buku dan sumber informasi yang berhubungan dengan objek yang diteliti.

\section{Metode Pengumpulan Data}

\section{Data Primer}

Data primer adalah data yang dikumpulkan secara langsung dari objek yang diteliti.

2. Data sekunder

Data yang diperoleh peneliti dari kantor Desa KembangSeri Kecamatan Bermani Ilir Kabupaten Kepahiang Provinsi Bengkulu.
D. Spesifikasi Hardware dan Software

1. Perangkat Keras

Perankat keras untuk membangun sistem adalah sebuah Laptop dengan spesifikasi :
a. Processor $2 \mathrm{Ghz}$
b. RAM $1 \mathrm{~Gb}$
c. Harddisk $500 G b$

2. Perangkat Lunak
a. Sistem Operasi Windows
b. Office 2007
c. Bahasa Pemrograman Vb Net.

\section{E. Tahapan Penelitian}

Tahapan penelitian dimulai dari beberapa hal yang akan dilakukan terlihat dari alir diagram sebagi berikut:

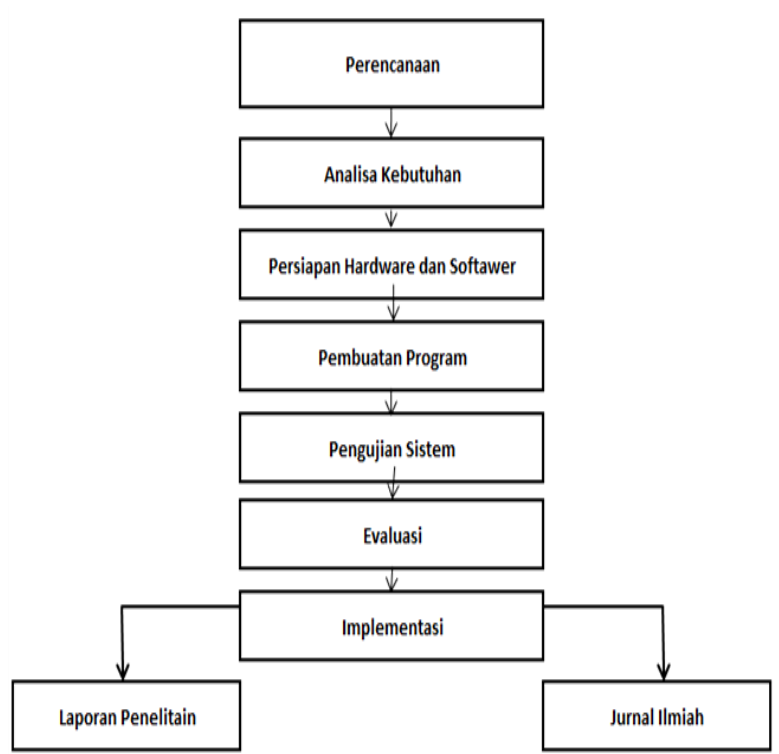

Gambar 4. Diagram Alir Tahapan Penelitian

\section{F. Implementasi dan Pengujian}

Penyusunan laporan jumlah penduduk Desa Kembangsri Kecamatan Bermani Ilir Kabupaten Kepahiang Provinsi Bengkulu mudah efien dan efektif. a. Pengujian Aplikasi yaitu menggunakan pendekatan aplikasi black box testing dengan program, apakah aplikasi ini sudah sesuai dengan yangdiharapkan.

b. Intergrasi Sistem, pengujian yang dilakukan dengan menginstal sistem aplikasi yang telah dibuat.

\section{G. Metode Perancangan Sistem}

1. Analisis Sistem Aktual

Desa Kembangsri Kecamatan Bermani Ilir Kabupaten Kepahiang Provinsi Bengkulu salah satu lembaga pemerintah yang masih menggunakan cara manual untuk membuat suatu laporan jumlah penduduk dan belum ada tata 
kelola yang baik mengenai pengarsipan atau pengbackup data penduduk desa Kembangseri.

Oleh karena itu dibutuhkan suatu sistem database yang mampu memberikan kemudahan untuk proses pengelolaan data jumlah penduduk dan lainnya.

2. Analisis Sistem Baru

Sistem Pelaporan jumlah penduduk desa kembangseri kecamatan Bermani Ilir Kabupaten Kepahiang Provinsi Bengkulu.

H. Diagaram Konteks DFD (Data Flow Diagram)

1. Diagram Konteks

Pelaporan Jumlah Penduduk Desa Kembangseri Kecamatan Keban Bermani Kabupaten Kepahiang Provinsi Bengkulu seperti gambar 3.1. dibawah ini :

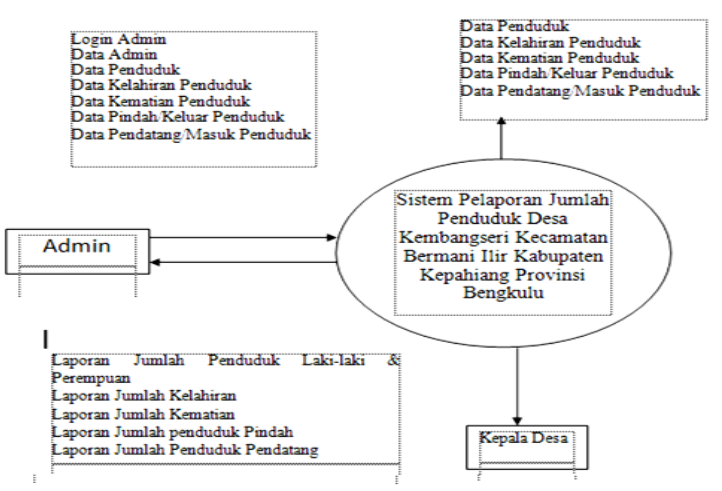

Gambar 5. Diagram Konteks DFD

\section{Rancangan File Database}

Rancangan file pada sistem administrasi pelayanan masyarakat pada Kantor Desa Kembang Seri Kecamatan Bermani Ilir Kabupaten Kepahiang, antara lain :

1. File Penduduk

Nama File : tblpenduduk

Kunci Utama : kdpenduduk

Kunci Tamu : -

Tabel 1. Penduduk

\begin{tabular}{|c|l|c|c|l|}
\hline No & Nama Field & Tipe Data & Ukuran & Keterangan \\
\hline 1. & Kdpenduduk & Varchar & 20 & $\begin{array}{l}\text { Kode } \\
\text { Penduduk }\end{array}$ \\
\hline 2. & Nokk & Varchar & 20 & $\begin{array}{l}\text { No Kartu } \\
\text { Keluarga }\end{array}$ \\
\hline 3. & Hubkeluarga & Varchar & 30 & $\begin{array}{l}\text { Hubungan } \\
\text { Dalam } \\
\text { Keluarga }\end{array}$ \\
\hline 4. & Nmpenduduk & Varchar & 50 & $\begin{array}{l}\text { Nama } \\
\text { Penduduk }\end{array}$ \\
\hline 5. & Tmtlahir & Varchar & 30 & Tempat Lahir \\
\hline 6 & Tgllahir & Datetime & 10 & Tanggal Lahir \\
\hline 7 & Jk & Varchar & 15 & Jenis Kelamin \\
\hline 8 & $\begin{array}{l}\text { Warganega } \\
\text { ra }\end{array}$ & Varchar & 25 & $\begin{array}{l}\text { Kewarganega } \\
\text { raan }\end{array}$ \\
\hline 9. & Status & Varchar & 20 & $\begin{array}{l}\text { Status } \\
\text { Perkawinan }\end{array}$ \\
\hline
\end{tabular}

\begin{tabular}{|c|l|c|c|l|}
\hline No & Nama Field & Tipe Data & Ukuran & Keterangan \\
\hline 10 & Agama & Varchar & 20 & Agama \\
\hline 11. & Pekerjaan & Varchar & 15 & Pekerjaan \\
\hline 12. & Alamat & Varchar & 100 & Alamat \\
\hline 13. & RT & Numeric & 3 & RT \\
\hline 14. & RW & Numeric & 3 & RW \\
\hline 15 & Nmibu & Varchar & 50 & Nama Ibu \\
\hline 16 & Nmayah & Varchar & 50 & Nama Ayah \\
\hline 17 & Ket & Varchar & 50 & Keterangan \\
\hline
\end{tabular}

2. File Kelahiran

Nama File : tblkelahiran

Kunci Utama : kdkelahiran

Kunci Tamu : -

Tabel 2. Kelahiran

\begin{tabular}{|c|l|c|c|l|}
\hline No & Nama Field & $\begin{array}{c}\text { Tipe } \\
\text { Data }\end{array}$ & Ukuran & Keterangan \\
\hline 1. & $\begin{array}{l}\text { Kdkelahira } \\
\mathrm{n}\end{array}$ & Varchar & 20 & Kode Kelahiran \\
\hline 2. & Nama & Varchar & 50 & Nama \\
\hline 3. & Tmtlahir & Varchar & 30 & Tempat Lahir \\
\hline 4. & Tgllahir & Datetime & 10 & Tanggal Lahir \\
\hline 5. & Jk & Varchar & 15 & Jenis Kelamin \\
\hline 6. & Agama & Varchar & 15 & Agama \\
\hline 7. & Nmbapak & Varchar & 50 & Nama Bapak \\
\hline 8. & Nmibu & Varchar & 50 & Nama Ibu \\
\hline 9. & Kerjabapak & Varchar & 15 & $\begin{array}{l}\text { Pekerjaan } \\
\text { Bapak }\end{array}$ \\
\hline 10. & Kerjaibu & Varchar & 15 & Pekerjaan Ibu \\
\hline 11 & $\begin{array}{l}\text { Suratpenga } \\
\text { ntarrt }\end{array}$ & Image & - & $\begin{array}{l}\text { Scan Surat } \\
\text { Pengantar RT }\end{array}$ \\
\hline 11. & Keterangan & Varchar & 50 & Keterangan \\
\hline
\end{tabular}

3. File Kematian

Nama File : tblkematian

Kunci Utama : kdkematian

Kunci Tamu : kdpenduduk

\begin{tabular}{|c|l|l|c|l|}
\hline \multicolumn{5}{|c}{ Tabel 3. Kematian } \\
\hline No & Nama Field & $\begin{array}{l}\text { Tipe } \\
\text { Data }\end{array}$ & Ukuran & Keterangan \\
\hline 1. & Kdkematian & Varchar & 15 & $\begin{array}{l}\text { Kode } \\
\text { Kematian }\end{array}$ \\
\hline 2. & Kdpenduduk & Varchar & 20 & $\begin{array}{l}\text { Kode } \\
\text { Penduduk }\end{array}$ \\
\hline 3. & Tmtmeniggal & Varchar & 30 & $\begin{array}{l}\text { Tempat } \\
\text { Meninggal }\end{array}$ \\
\hline 4. & Tglmeninggal & Datetime & 10 & $\begin{array}{l}\text { Tanggal } \\
\text { Meninggal }\end{array}$ \\
\hline 5. & Sebabmeninggal & Varchar & 50 & $\begin{array}{l}\text { Sebab } \\
\text { Meninggal }\end{array}$ \\
\hline 6 & Suratpengantarrt & Image & - & $\begin{array}{l}\text { Scan Surat } \\
\text { Pengantar } \\
\text { RT }\end{array}$ \\
\hline 7 & Ket & & & Keterangan \\
\hline
\end{tabular}

4. File Pindah Keluar

Nama File : tblpindah

Kunci Utama : kdpindah

Kunci Tamu : kdpenduduk

Tabel 4. Pindah Keluar

\begin{tabular}{|c|l|l|l|l|}
\hline No & Nama Field & $\begin{array}{c}\text { Tipe } \\
\text { Data }\end{array}$ & Ukuran & Keterangan \\
\hline 1. & Kdpindah & Varchar & 15 & $\begin{array}{l}\text { Kode Pindah } \\
\text { Keluar }\end{array}$ \\
\hline 2. & Kdpenduduk & Varchar & 20 & $\begin{array}{l}\text { Kode } \\
\text { Penduduk }\end{array}$ \\
\hline 3. & Tglpindah & Datetime & 10 & $\begin{array}{l}\text { Tanggal } \\
\text { Pindah } \\
\text { Keluar }\end{array}$ \\
\hline
\end{tabular}




\begin{tabular}{|l|l|l|l|l|}
\hline No & Nama Field & $\begin{array}{c}\text { Tipe } \\
\text { Data }\end{array}$ & Ukuran & Keterangan \\
\hline 4. & Alamatpindah & Varchar & 100 & $\begin{array}{l}\text { Alamat } \\
\text { Pindah } \\
\text { Keluar }\end{array}$ \\
\hline 5 & Ket & Varchar & 50 & Keterangan \\
\hline
\end{tabular}

5. File Keterangan

a. Nama File : tblPindah

b. Kunci Utama : Pindah

c. Kunci Tamu : kdpindahpenduduk

Tabel 5. Penduduk Pindah

\begin{tabular}{|c|l|l|l|l|}
\hline No & Nama Field & $\begin{array}{c}\text { Tipe } \\
\text { Data }\end{array}$ & Ukuran & Keterangan \\
\hline 1. & Kd_Pindh & Varchar & 20 & $\begin{array}{l}\text { Kode_Pindh } \\
\text { Penduduk }\end{array}$ \\
\hline 2. & Nmr_kk & Varcha & 10 & Nomot KK \\
\hline 3. & Tgl_pindh & Varchar & 20 & $\begin{array}{l}\text { Tanggal } \\
\text { Pindah }\end{array}$ \\
\hline 4. & Almt_Asal & Varchar & 150 & Alamat Asal \\
\hline 5 & Alm__Pindah & Varchar & & $\begin{array}{l}\text { Alamat } \\
\text { Pindah }\end{array}$ \\
\hline 6 & $\begin{array}{l}\text { Srt_Pengtr } \\
\text { RT }\end{array}$ & image & - & $\begin{array}{l}\text { Scan Surat } \\
\text { Pegantar RT }\end{array}$ \\
\hline
\end{tabular}

\section{Admin}

Nama File : tbladmin

Kunci Utama : username

Kunci Tamu : -

Tabel 6. Admin

\begin{tabular}{|l|l|l|l|l|}
\hline No & Nama Field & $\begin{array}{c}\text { Tipe } \\
\text { Data }\end{array}$ & Ukuran & Keterangan \\
\hline 1. & Username & Varchar & 10 & $\begin{array}{l}\text { Username } \\
\text { Admin }\end{array}$ \\
\hline 2. & Password & Varchar & 10 & $\begin{array}{l}\text { Password } \\
\text { Admin }\end{array}$ \\
\hline 3. & Nmlengkap & Varchar & 35 & $\begin{array}{l}\text { Nama } \\
\text { Lengkap }\end{array}$ \\
\hline
\end{tabular}

\section{J. Rancangan Struktur Menu}

Adapun rancangan struktur menu sistem administrasi pelayanan masyarakat Pada Kantor Desa Kembang Seri Kecamatan Bermani Ilir Kabupaten Kepahiang, terlihat pada gambar 6 .

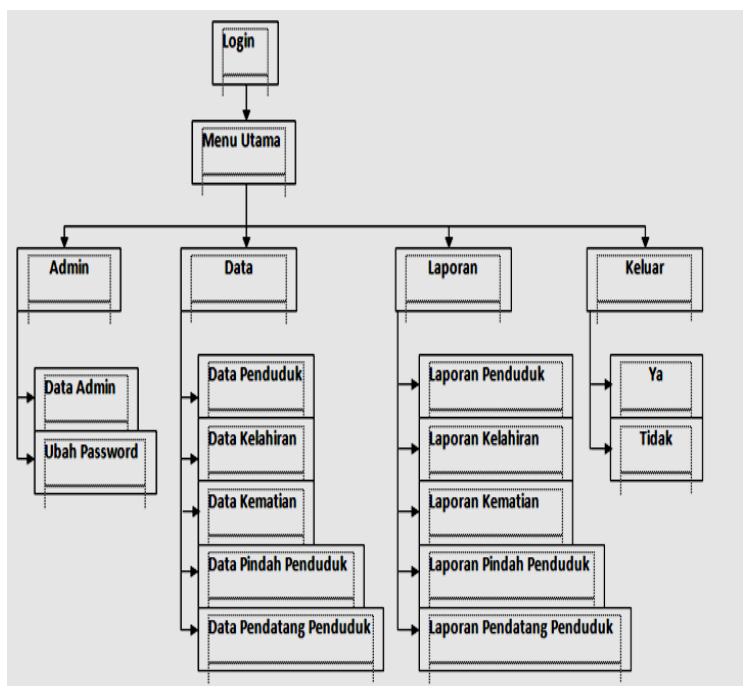

Gambar 6. Struktur Menu

\section{HASIL DAN PEMBAHASAN}

\section{A. Hasil dan Pembahasan}

Yang didapat sebuah Aplikasi / program khusus yang dapat digunakan dalam sistem pelaporan jumlah penduduk Desa Kembangseri Kecamatan Bermani Ilir Kabupaten Kepahiang Provinsi Bengkulu dimana saat ini sangat dibutuhkan, karena pada faktanya data yang ada dikantor desa tidak sesuai dengan yang ada dilapangan.

Sistem merupakan satu aplikasi yang dapat membantu perangkat desa untuk Pengolahan data yang dimaksud data penduduk, kematian, kelahiran, serta pindah keluar penduduk dari desa kembangseri

Hanya memasukan username dan password yang benar.

a. Menu Logi

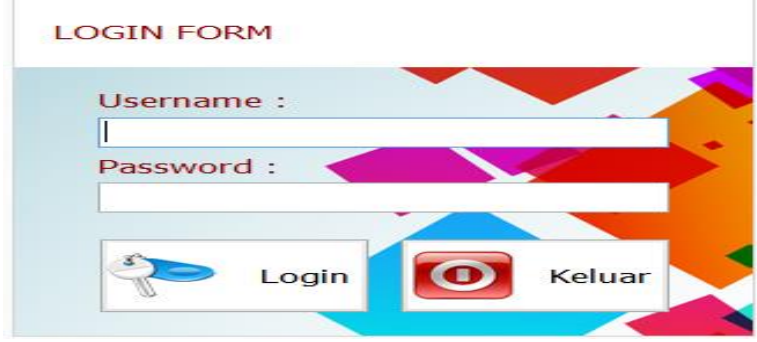

Gambar 7. Menu Login

b. Menu Utama

Menu utama menampilkan pilihan yang akan dikelolah antara lain : Pengaturan: Data Admin, Ubah Pasword dan Keluar, Sedangkan Data yaitu Data domisili Penduduk, Data Kelahiran, Data Kematian dan Data Penduduk Pindah dan datang seperti gambar dibawah ini :

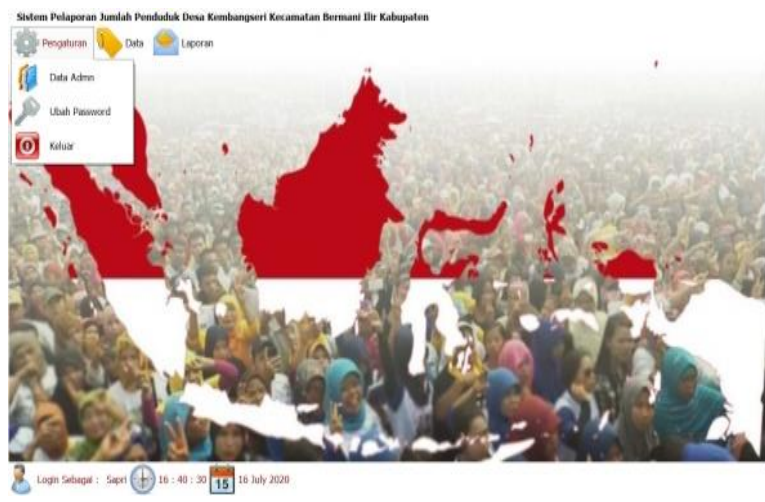

Gambar 8. Menu Utama

c. From Input Data Domisili Penduduk

Form data domisili penduduk digunakan untuk mengolah data domisili penduduk tetap didesa kembangseri. Pengolahan data yang dapat dilakukan yaitu dengan menambah, mengubah, serta menghapus data domisili penduduk desa kembangseri. Adapun form data domisili penduduk, seperti pada gambar dibawah ini : 


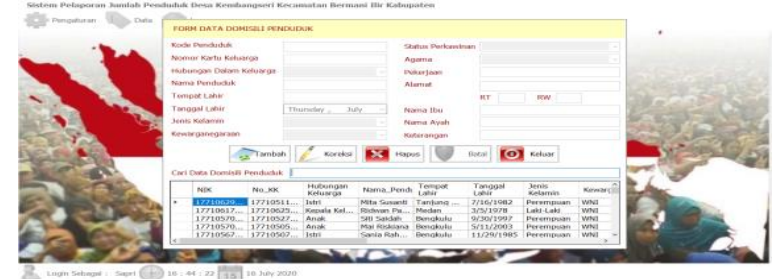

Gambar 9. Input Data Domisili Penduduk

d. Data Kematian Penduduk

Data Kematian penduduk desa Kembangseri seperti pada gambar dibawah ini.

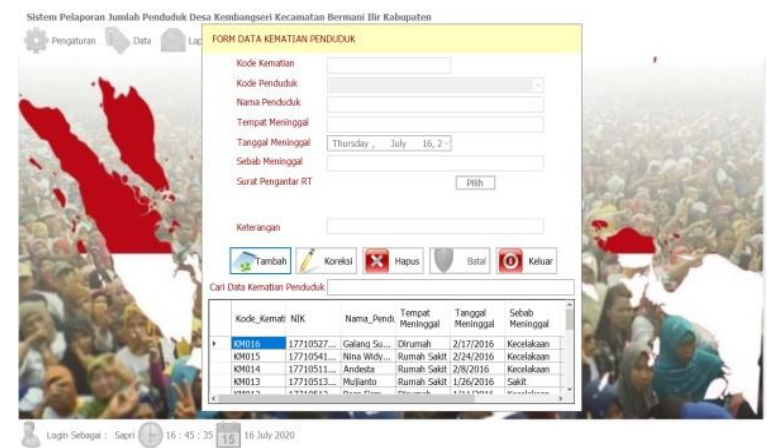

Gambar 10. Input Data Kematian Penduduk

e. Data Kelahiran Penduduk

Data Kelahiran digunakan untuk mengolah data kelahiran penduduk di desa kembangseri. Pengolahan data yang dilakukan yaitu dengan menambah, mengubah, serta menghapus data Kelahiran penduduk desa kembangseri. seperti pada gambar dibawah ini.

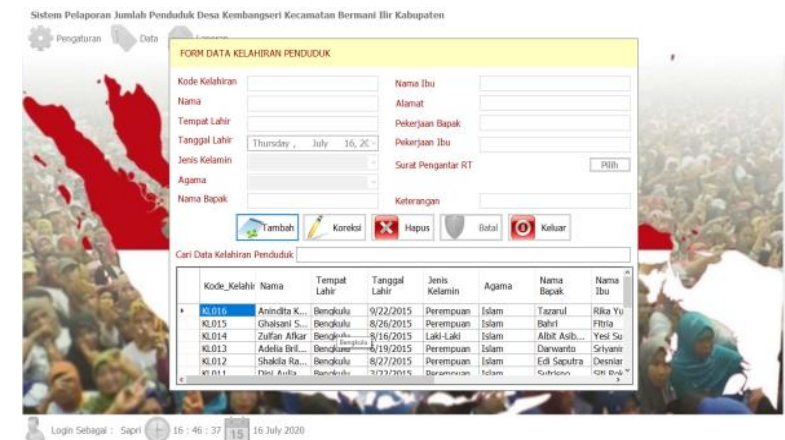

Gambar 11. Input Data Kelahiran Penduduk

f. Data Pindah Penduduk

Data pindah penduduk digunakan untuk mengolah data pindah penduduk di desa kembangseri. Pengolahan data yang dapat dilakukan yaitu dengan menambah, mengubah, serta menghapus data pindah penduduk desa kembangseri. seperti pada gambar dibawah ini.

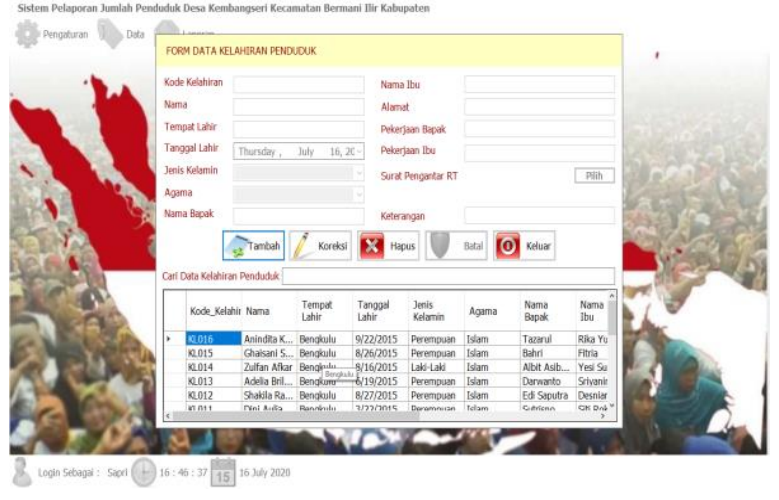

Gambar 12. Input Data Pindah Penduduk

g. Data Penduduk Masuk

Data penduduk masuk digunakan untuk mengolah data penduduk masuk di desa kembangseri. Pengolahan data yang dapat dilakukan yaitu dengan menambah, mengubah, serta menghapus data penduduk masuk desa kembangseri. seperti pada gambar dibawah ini.

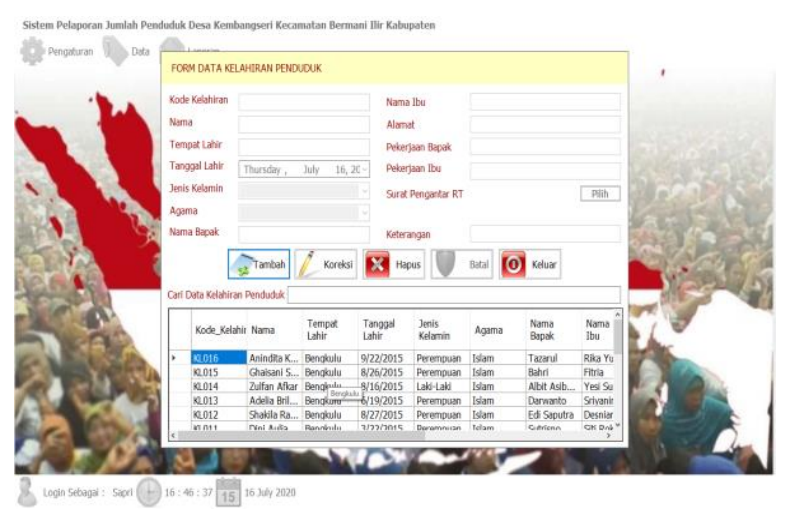

Gambar 13. Input Data Datang Penduduk

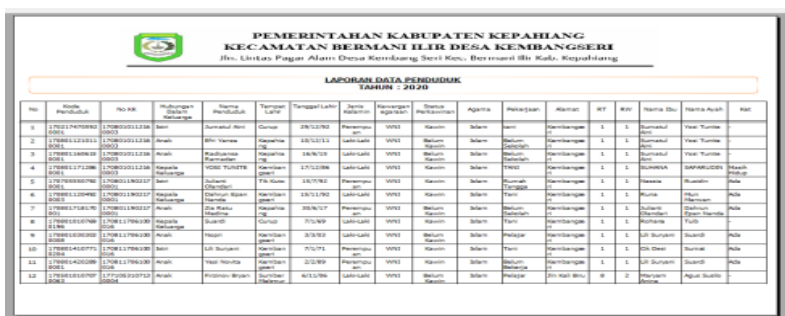

Gambar 14. Laporan Data Domisili Penduduk

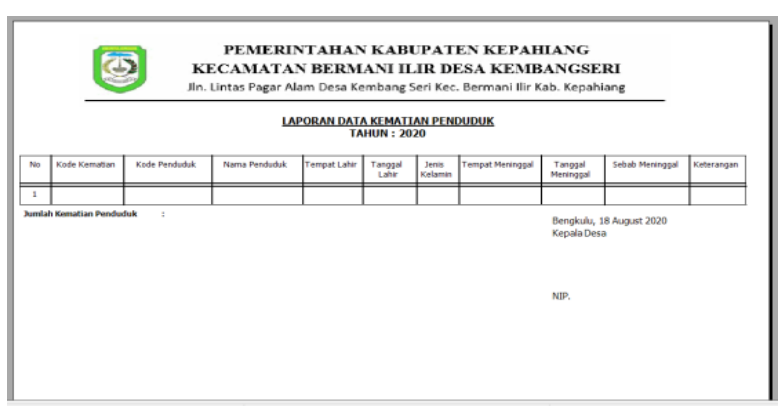

Gambar 15. Laporan Data Kematian Penduduk 


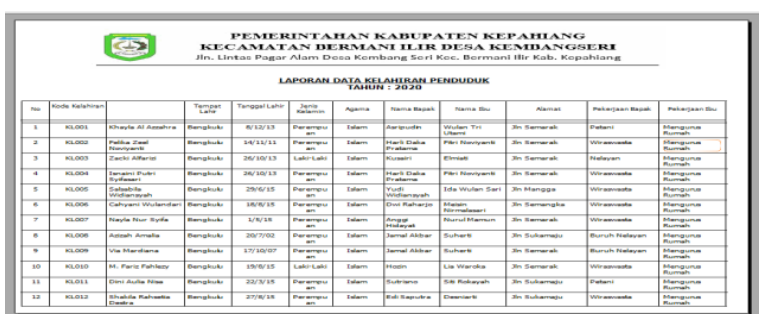

Gambar 16. Laporan Data Kelahiran Penduduk

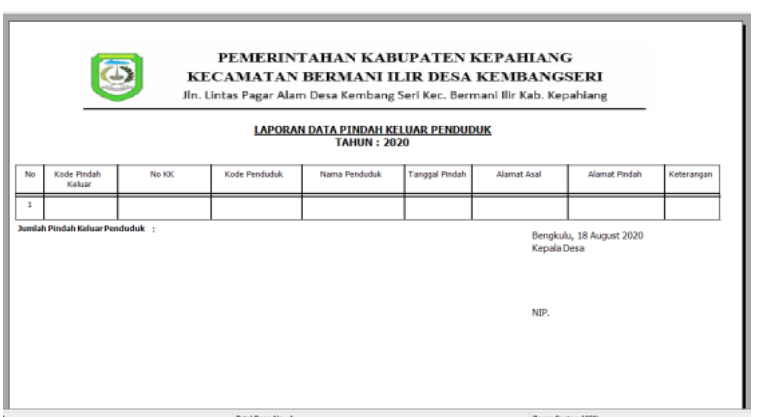

Gambar 17. Laporan Data Pindah Penduduk

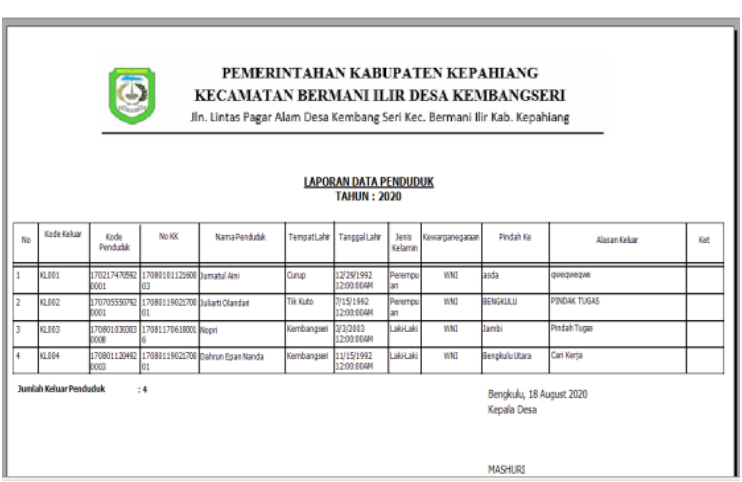

Gambar 18. Laporan Penduduk Keluar

\section{PENUTUP}

\section{A. Kesimpulan}

Pertambahan jumlah penduduk pada suatu wilayah akan selalu berpengaruh terhadap penggunaan teknologi. Khususnya di desa Kembang Seri Kecamatan Bermani Ilir Kabupaten Kepahiang Provinsi Bengkul saat ini belum menggunakan teknologi sebagai mana mestinya. Pelayanan pada masyarakat masih mengalami kendala dalam pengolahan data, sehingga terjadi perbedaan data yang ada di kantor desa dengan data yang ada dilapangan. Dapat disimpulkan dengan menggunakan sistem aplikasi pemrograman khusus (Visual Basic Net) dapat mempermudah dalam mengolah data secara cepat, tepat dalam pekerjaan.

\section{B. Saran}

1. Bagi pihak pengguna atau perangkat desa harus dapat mempelajari/menggunakan sistem ini dan diwajibkan untuk mengikuti pelatihan-pelatihan mengenai pelaporan serta mengikuti perkembangan zaman teknologi secara global sehingga dapat bersaing tepat guna.

2. Bagi Masyarakat sebaiknya memberikan informasi data yang sebenarnya sehingga data yang ada dikantor desa sama dengan data yang ada dilapangan.

\section{DAFTAR PUSTAKA}

[1] Kusrini.. Konsep dan Aplikasi Sistem Pendukung Keputusan. Penerbit Andi, Yogyakarta. 2007.

[2] Lembaga Demografi Fakultas Ekonomi UI. Dasar-Dasar Demografi. Lembaga Penerbit FEUI.Jakarta. 1981.

[3] Said Rusli. Pengantar Ilmu Kependudukan. LP3ES. Jakarta 1983.

[4] Mantra, Ida Bagoes. Demografi Umum. Pusata Pelajar. Yogyakarta: 2000.

[5] Pressman R.S Software Engineering : a pactitioner's approach. New York : McGrawHill. 2010.

[6] Ariyanto dan Taufik, "Pengaruh Struktur Pemegang Saham terhadap Struktur Modal Perusaan", Jurnal Manajemen Indonesia, Vol.2, no.1; 64-71. 2002.

[7] Junindar. Panduan Lengkap Menjadi Programmer Membuat Aplikasi Pernjualan Menggunakan VB. Net. Penerbit : Media Kita. 2008.

[8] Hernita, P. Kupas Tuntas Database Server 2008. Penerbit Andi. Yogyakarta. 2010.

[9] SmitDev. Kupas Tuntas Database Server 2008. Cybertron Solution. Penerbit Andi. 2010. 